\title{
Extracellular deposition of mouse senile AApoAll amyloid fibrils induced different unfolded protein responses in the liver, kidney, and heart
}

\author{
Hongmin Luo ${ }^{1,2}$, Jinko Sawashita ${ }^{1,3}$, Geng Tian ${ }^{1,4}$, Yingye Liu ${ }^{1}, \mathrm{Lin}_{\mathrm{Li}}{ }^{1}$, Xin Ding ${ }^{1}$, Zhe Xu${ }^{1}, \mathrm{Mu}$ Yang ${ }^{1}$, \\ Hiroki Miyahara', Masayuki Mori ${ }^{1,5}$, Jinze Qian ${ }^{1,6}$, Yaoyong Wang ${ }^{1}$ and Keiichi Higuchi ${ }^{1,3}$
}

Mouse senile amyloidosis is a disorder in which apolipoprotein A-II deposits extracellularly in many organs as amyloid fibrils (AApoAll). In this study, we intravenously injected $1 \mu \mathrm{g}$ of isolated AApoAll fibrils into R1.P1-Apoa2 ${ }^{C}$ mice, to induce AApoAll amyloidosis. We observed that the unfolded protein response was induced by deposition of AApoAll amyloid. We found that the mRNA and the protein expression levels of heat shock protein A5 (HSPA5; also known as glucoseregulated protein 78) were increased in the liver with AApoAll amyloid deposits. Immunohistochemistry showed that HSPA5 was only detected in hepatocytes close to AApoAll amyloid deposits. Furthermore, gene transcription of several endoplasmic reticulum (ER) stress-related proteins increased, including eukaryotic translation initiation factor 2 alpha kinase 3 (Eif2ak3), activating transcription factor 6 (Atf6), activating transcription factor 4 (Atf4), X-box-binding protein 1 splicing (Xbp1s), DNA-damage inducible transcript 3 (Ddit3), and autophagy protein 5 (Atg5). Moreover, apoptosis-positive cells were increased in the liver. Similar results were seen in the kidney but not in the heart. Our study indicates that ER stress responses differed among tissues with extracellular AApoAll amyloid fibril deposition. Although upregulated HSPA5 and the activated unfolded protein response might have roles in protecting tissues against aggregated extracellular AApoAll amyloid deposition, prolonged ER stress induced apoptosis in the liver and the kidney.

Laboratory Investigation (2015) 95, 320-333; doi:10.1038/labinvest.2014.158; published online 29 December 2014

Amyloidosis refers to a group of protein-folding disorders characterized by accumulation of fine amyloid fibrils to which normally innocuous soluble proteins polymerize. ${ }^{1}$ Amyloid fibrils deposit mainly in extracellular spaces. Currently, more than 28 different kinds of human proteins, intact or in fragmented forms, have been found to be amyloidogenic in vivo and to be associated with pathological disorders such as Alzheimer's disease (AD), prion diseases, type II diabetes, reactive amyloid A (AA) amyloidosis, familial amyloid polyneuropathy (FAP), senile systemic amyloidosis, and dialysis-related amyloidosis, in familial and sporadic manners. ${ }^{2,3}$

In mice, apolipoprotein A-II (ApoA-II), the second most abundant protein in serum high-density lipoprotein, accumulates to form amyloid fibrils (AApoAII) and deposits systemically (but not in the brain or bone), leading to ageassociated systemic amyloidosis (AApoAII amyloidosis). ${ }^{4,5}$ Three major variants of ApoA-II (types A, B, and C) with different amino acid substitutions at four positions (positions 5, 20, 26, and 38 from the $\mathrm{N}$ terminus) are present among laboratory mouse strains. ${ }^{6,7}$ The strains with the variant C type ApoA-II (APOAIIC, Gln5, and Ala38) spontaneously exhibit a high incidence of amyloidosis and severe amyloid deposition with aging. ${ }^{8}$ R1.P1-Apoa $2^{c}$ mice are a congenic strain of mice that have the amyloidogenic allele type $\mathrm{C}$ of the apoA-II gene from the senescenceaccelerated mouse prone 1 (SAMP1) strain on the genetic background of the senescence-accelerated mouse resistant 1 strain. ${ }^{9}$ In previous studies, we found that intravenous injection of a very small amount of AApoAII fibrils $\left(\sim 10^{-13} \mathrm{~g}\right)$

${ }^{1}$ Department of Aging Biology, Institute of Pathogenesis and Disease Prevention, Shinshu University Graduate School of Medicine, Matsumoto, Japan; ${ }^{2}$ Third Hospital of Hebei Medical University, Shijiazhuang, China; ${ }^{3}$ Department of Biological Sciences for Intractable Neurological Diseases, Institute for Biomedical Sciences, Interdisciplinary Cluster for Cutting Edge Research, Shinshu University, Matsumoto, Japan; ${ }^{4}$ Shijiazhuang Obstetrics and Gynecology Hospital, Shijiazhuang, China;

${ }^{5}$ Department of Advanced Medicine for Health Promotion, Institute for Biomedical Sciences, Interdisciplinary Cluster for Cutting Edge Research, Shinshu University, Matsumoto, Japan and ${ }^{6}$ Department of Pathology, Hebei Medical University, Shijiazhuang, China

Correspondence: Dr K Higuchi, PhD, Department of Aging Biology, Institute of Pathogenesis and Disease Prevention, Shinshu University Graduate School of Medicine, 3-1-1 Asahi, Matsumoto 390-8621, Japan.

E-mail: keiichih@shinshu-u.ac.jp

Received 17 December 2013; revised 10 September 2014; accepted 11 September 2014 
isolated from the livers of old R1.P1-Apoa $2^{c}$ mice markedly accelerated amyloid deposition in young R1.P1-Apoa $2^{c}$ mice. ${ }^{10}$ Thus, AApoAII amyloidosis could be transmitted by a prion-like infectious process through a seedingnucleation mechanism. ${ }^{11}$ AApoAII amyloidosis can also be transmitted by the feces ${ }^{12}$ or milk secreted from affected mice. ${ }^{13}$ However, the pathophysiology involved in AApoAII amyloidosis is unclear.

The endoplasmic reticulum (ER) integrates protein synthesis and folding, calcium storage, and signaling. Several cellular stress conditions, such as accumulation of misfolded proteins and alterations in $\mathrm{Ca}^{2+}$ homeostasis, can cause ER dysfunction and misfolding of proteins, ${ }^{14}$ leading to a phenomenon known as ER stress. To reestablish protein homeostasis and normal ER function, mammalian cells evolved a coordinated response of protein signaling pathways termed the unfolded protein response (UPR). Heat shock protein A5 (HSPA5), also known as glucose-regulated protein 78 , is a key mediator of the UPR. ER stress leads to dissociation of HSPA5 from three 'stress sensor' proteins and thereby activates them: (1) activating transcription factor 6 (ATF6); (2) ER to nucleus signaling 1 (ERN1), also known as inositol requiring enzyme 1 (IRE1); and (3) eukaryotic translation initiation factor 2 alpha kinase 3 (EIF2AK3), also known as protein kinase RNA-like ER kinase (PERK). It is now widely accepted that the specific induction of HSPA5 is indicative of ER stress due to its key role in the regulation of ER stress signaling. All three branches of the UPR are rapidly activated in response to the onset of ER stress and co-operatively function to emit pro-survival signals. However, under prolonged or excessive ER stress, the UPR is not sufficient to restore homeostasis, and it can lead to cell death ${ }^{15}$ and to disease. ${ }^{16-18}$

ER stress is involved in amyloidosis such as $\mathrm{AD}^{19}$ and type II diabetes. ${ }^{20}$ In vitro, ER stress responses are initiated by exposure to extracellular amyloid aggregate or oligomers. ${ }^{21-23}$ Moreover, the ER stress response has been induced in vivo in neurons that were exposed to extracellular deposition of transthyretin (TTR), thereby initiating amyloidosis. ${ }^{24}$ AApoAII amyloid can deposit in the extracellular spaces of many organs, resulting in AApoAII amyloidosis and reduced life span. Based on these observations, we hypothesized that ER stress responses were induced by extracellular AApoAII amyloid deposition. In this study, we demonstrate that ER stress was indeed induced by AApoAII amyloid fibril deposition in the liver and the kidneys, but not in the heart. Deposition promoted the induction of ER chaperone HSPA5 and UPR conferring resistance to aggregated protein toxicity in hepatocytes and renal cells. However, prolonged ER stress induced apoptosis in hepatocytes and renal cells.

\section{MATERIALS AND METHODS}

\section{Animals}

R1.P1-Apoa ${ }^{c}$ mice were raised in the Division of Laboratory Animal Research, Department of Life Science, Research
Center for Human and Environmental Sciences, Shinshu University, Matsumoto, Japan. Mice were maintained under specific pathogen-free conditions at $24 \pm 2{ }^{\circ} \mathrm{C}$, with a lightcontrolled regimen ( $12 \mathrm{~h}$ light/dark cycles). A commercial diet (MF; Oriental Yeast, Tokyo, Japan) and tap water were available ad libitum. Only female mice were used in this study, to avoid AA amyloidosis or other adverse impacts caused by fighting and other behaviors among mice reared in the same cage. Mice were killed by cardiac puncture under diethyl ether anesthesia. All experiments were performed with approval of the Committee for Animal Experiments of Shinshu University.

\section{Isolation of Amyloid Fibrils}

AApoAII fibrils were isolated as described previously, ${ }^{11,25-27}$ from the livers of 9-month-old R1.P1-Apoa $2^{c}$ mice in which severe amyloid deposition had been induced by intravenous injection of AApoAII fibrils at 2 months of age. The amyloidladen liver $(1.0 \mathrm{~g})$ was homogenized with a Polytron homogenizer ( $\mathrm{T} 25$ digital ULTRA-TURRAX, IKA, Osaka, Japan) in $10 \mathrm{ml}$ of ice-cold $0.15 \mathrm{M} \mathrm{NaCl}$ using three cycles of $30 \mathrm{~s}$ agitation at $30 \mathrm{~s}$ intervals. The mixture was centrifuged at $4 \times 10^{4} \mathrm{~g}$ for $20 \mathrm{~min}$ at $4{ }^{\circ} \mathrm{C}$, after which the supernatant was discarded. These operations were repeated 10 to 14 times before the supernatant had an optical absorbance $<0.3$ at $280 \mathrm{~nm}$. The pellet of the final centrifugation was rinsed with $10 \mathrm{ml}$ of distilled water (DW) by $30 \mathrm{~s}$ of homogenization and was centrifuged at $4 \times 10^{4} \mathrm{~g}$ for $20 \mathrm{~min}$ after which the supernatant was discarded. The amyloid fibril fraction was extracted in $10 \mathrm{ml}$ of DW by homogenization for $30 \mathrm{~s}$ and centrifuged at $3 \times 10^{4} \mathrm{~g}$ for $20 \mathrm{~min}$ at $4{ }^{\circ} \mathrm{C}$. This extraction procedure was repeated three to six times. Isolated amyloid fibrils in the supernatant were further purified by pelleting by ultracentrifugation at $10^{5} \mathrm{~g}$ for $1 \mathrm{~h}$ at $4{ }^{\circ} \mathrm{C}$. Isolated amyloid fibrils were resuspended in DW at a concentration of $1.0 \mathrm{mg} / \mathrm{ml}$.

\section{Induction of AApoAll Amyloidosis and Preparation of Animal Tissue Samples}

We placed $1 \mathrm{ml}$ of amyloid fibril solution into a $1.5-\mathrm{ml}$ Eppendorf tube at a concentration of $10 \mu \mathrm{g} / \mathrm{ml}$ and sonicated it on ice for $30 \mathrm{~s}$, using an ultrasonic homogenizer VP-5S (Tietech, Tokyo, Japan) at moderate power. This procedure was repeated three times at 30-s intervals. Sonicated AApoAII amyloid samples were used immediately.

Twelve 2-month-old female R1.P1-Apoa $2^{c}$ mice were injected intravenously with $1 \mu \mathrm{g}$ each AApoAII fibrils, to induce AApoAII amyloidosis. Six were killed after 2 months and the other six were killed after 4 months. One 9-month-old and two 13-month-old female R1.P1-Apoa2 $2^{c}$ mice showed spontaneous amyloid deposition without injection of amyloid seeds. Those three mice were killed. They had been kept in the room in which injection of seeds was routinely conducted and spontaneous amyloidosis was observed in old mice. In addition, we killed three aged, 15-month-old female 
R1.P1-Apoa2 ${ }^{c}$ mice that had been maintained in another room, in which mouse AApoAII amyloidosis had not been induced by seeding and in which amyloidosis had not been observed.

The mice were euthanized by cardiac puncture under diethyl ether anesthesia, and major tissues were dissected. Half of the tissues were kept at $-80^{\circ} \mathrm{C}$ and the other half was fixed in $10 \%$ neutral buffered formalin, embedded in paraffin, and cut into $4-\mu \mathrm{m}$ sections. Six female R1.P1Apoa $2^{c}$ mice injected with DW were killed after 2 or 4 months as controls.

\section{Detection of Amyloid Deposition}

Deposition of amyloid fibrils in each mouse was identified by polarizing microscopy using Congo Red-stained sections, where green birefringence indicates the presence of amyloid fibrils. The extent of amyloid deposition was determined semiquantitatively in Congo Red-stained sections, using the amyloid score as a parameter, which was graded from 0 to 4 in each organ as previously described. ${ }^{11}$ The amyloid index (AI) parameter represents the average degree of deposition in seven organs (heart, liver, spleen, stomach, intestine, tongue, and skin).

The amount of AApoAII deposited in each organ was generally categorized as follows: grade 0 , no AApoAII; grade 1 , a minute amount; grade 2, small amounts; grade 3 , a moderate amount; and grade 4, extensive AApoAII deposits. ${ }^{11}$ More specifically, the criteria for each grade in the liver, kidney, and heart were as follows. Grade 2 included deposits only in the periportal areas of the liver, only in collecting tubules in the papillae and in the medulla nephrica of the kidneys, and only in the interstitial tissues covering $10 \%$ of the areas of both ventricles, atrioventriclar septum, and both atria of the heart. Grade 3 included deposits with a moderate amount of AApoAII in $<30 \%$ of the area of the lobules of the liver, a moderate amount of AApoAII in both the kidney medulla and cortex including the glomerulus, and a moderate amount of AApoAII in the interstitial tissues covering $10-30 \%$ of the area of the heart muscles. Grade 4 consisted of extensive AApoAII deposits in $30-80 \%$ of the area of the lobules of the liver, extensive AApoAII deposits in $>30 \%$ of the area of the kidney medulla and cortex, $>30 \%$ of the glomerulus, and extensive AApoAII deposits in $>30 \%$ of the area of the heart muscles. The grading criteria in other organs were described previously. ${ }^{11}$

Amyloid fibril proteins were identified by immunohistochemistry using the avidin-biotin horseradish peroxidase (HRP) complex method. Specific antisera against mouse AApoAII and mouse AA were used. ${ }^{28}$ Tissues were examined by two independent observers who were blinded to the experimental protocol.

RNA Extraction and Analysis of mRNA Expression by RTPCR and Real-Time Quantitative RT-PCR

Total RNA was extracted from tissues using TRIZOL Reagent (Invitrogen, Carlsbad, CA), after which the samples were treated with DNA-Free (Ambion, Austin, TX) to remove contaminating DNA and subjected to reverse transcription using a High Capacity cDNA Reverse Transcription Kit (Applied Biosystems, Carlsbad, CA). The cycling parameters for semiquantitative reverse transcriptase-PCR (RT-PCR) amplification were as follows: initial denaturation for $1 \mathrm{~min}$ at $94^{\circ} \mathrm{C}$, followed by 23 cycles of $30 \mathrm{~s}$ at $94^{\circ} \mathrm{C}, 30 \mathrm{~s}$ at $60^{\circ} \mathrm{C}$, and $45 \mathrm{~s}$ at $72^{\circ} \mathrm{C}$ for Gapdh; 28 cycles for hepatic and renal Hspa5; 32 cycles for cardiac Hspa5. Quantitative real-time RT-PCR analysis was carried out using an ABI PRISM 7500 Real Time PCR (Applied Biosystems) with SYBR Green (Takara Bio, Tokyo, Japan), and values were normalized with respect to Gapdh. The primers used are listed in Table 1.

\section{Western Blot Analysis}

Tissues were lysed in ice-cold RIPA lysis buffer (Santa Cruz Biotechnology, Santa Cruz, CA) supplemented with PhosSTOP phosphatase inhibitor (Roche Applied Science) and then sonicated. Samples of the resultant lysate $(25 \mu \mathrm{g})$ were separated by electrophoresis at $20 \mathrm{~mA}$ for $4 \mathrm{~h}$ on $12 \%$ SDSpolyacrylamide gels. After electrophoresis, proteins were

Table 1 The primers used for real time RT-PCR

\begin{tabular}{|c|c|c|}
\hline Gene symbols & & Sequences \\
\hline \multirow[t]{2}{*}{ Hspa5 } & Forward & 5'-ACCCCGAGAACACGGTCTT-3' \\
\hline & Reverse & 5'-TGCCCACCTCCAATATCAACT-3' \\
\hline \multirow[t]{2}{*}{ Eif2ak3 } & Forward & 5'-TCCGTTGCTGATTGGAAGGTC-3' \\
\hline & Reverse & 5'-CTTCTTCGCTGGCTGTGTAAC-3' \\
\hline \multirow[t]{2}{*}{ Atf4 } & Forward & 5'-CCTTCGACCAGTCGGGTTTG-3' \\
\hline & Reverse & 5'-CTGTCCCGGAAAAGGCATCC-3' \\
\hline \multirow[t]{2}{*}{ Atf6 } & Forward & 5'-TCGCCTITAGTCCGGTCTT-3' \\
\hline & Reverse & 5'-GGCTCCATAGGTCTGACTCC--3' \\
\hline \multirow[t]{2}{*}{ Ern1 } & Forward & 5'-ATGGCTACCATTATCCTGAGCA-3' \\
\hline & Reverse & 5'-TCCTGGGTAAGGTCTCCGTG-3' \\
\hline \multirow[t]{2}{*}{ Ddit3 } & Forward & $5^{\prime}$-TCCAGAAGGAAGTGCATCTTCA-3' \\
\hline & Reverse & 5'-GGACTCAGCTGCCATGACT-3' \\
\hline \multirow[t]{2}{*}{ Xbp1s } & Forward & 5'-GAGTCCGCAGCAGGTG-3' \\
\hline & Reverse & $5^{\prime}$-GTGTCAGAGTCCATGGGA-3' \\
\hline \multirow[t]{2}{*}{$\operatorname{Atg} 5$} & Forward & 5'-AGAGTCAGCTATTGACGTTGG-3' \\
\hline & Reverse & 5'-TGGACAGTGTAGAAGGTCCTIT-3' \\
\hline \multirow[t]{2}{*}{ Bax } & Forward & 5'-AGACACCTGAGCTGACCTTGGA-3' \\
\hline & Reverse & 5'-GAGACACTCGCTCAGCTTCTTG-3' \\
\hline \multirow[t]{2}{*}{$\mathrm{BCl}-2$} & Forward & $5^{\prime}$-TGTGAGGACCCAATCTGGAAA-3' \\
\hline & Reverse & 5'-TTGCAATGAATCGGGAGTTG-3' \\
\hline \multirow[t]{2}{*}{ Gapdh } & Forward & 5'-TGCACCACCAACTGCTTAG-3' \\
\hline & Reverse & 5'-GGATGCAGGGATGATGTTC-3' \\
\hline
\end{tabular}

RT-PCR, reverse transcriptase-PCR. 
transferred to a polyvinylidene difluoride $(0.45 \mu \mathrm{m}$ pore size; Millipore Corporation, Temecula, CA) membrane using a semidry western blotting apparatus at $150 \mathrm{~mA}$ for $2 \mathrm{~h}$. After blocking in $5 \%$ skim milk for $1 \mathrm{~h}$, the membranes were incubated overnight with primary antibodies against HSPA5 (1:1000; CST, Danvers, MA) and $\beta$-actin (1:5000; BWT, Louis Park, MN) in TBS containing $3 \%$ bovine serum albumin and $0.1 \%$ Tween- 20 at $4{ }^{\circ} \mathrm{C}$. Subsequently, membranes were incubated for $1 \mathrm{~h}$ with HRP-conjugated anti-rabbit IgG solution (1:3000). HSPA5 and $\beta$-actin were detected with the enhanced chemiluminescence system (Amersham Biosciences, Buckinghamshire, England). For quantification, western blot images were captured and analyzed using Scion Image 4.0.3.2 version (Frederick, MD).

\section{Immunohistochemistry}

Tissue sections were deparaffinized in Histoclear and dehydrated in an alcohol series. Endogenous peroxidase activity was inhibited with $3 \%$ hydrogen peroxide/ $100 \%$ methanol, and sections were blocked in 5\% fetal bovine serum and $1 \%$ bovine serum albumin in PBS. The following primary antibodies were used: rabbit polyclonal anti-HSPA5 (1:100; CST), polyclonal rabbit anti-mouse apoA-II (1:1500) and polyclonal rabbit anti-mouse AA $(1: 2000),{ }^{28}$ all of which were diluted in blocking solution and incubated overnight at $4{ }^{\circ} \mathrm{C}$. The negative control was prepared by omission of the first antibody to validate the specificity in each immunohistochemical staining.

\section{TUNEL Assay}

Formalin-fixed, paraffin-embedded tissue blocks were cut into $4-\mu \mathrm{m}$ sections and processed for use in the TUNEL assays. Sections were stained using the ApopTag Plus Peroxidase In Situ Apoptosis Detection Kit (EMD Millipore Corporation, Temecula, CA), according to the manufacturer's manual. The sample sections were treated with $25 \mu \mathrm{g} / \mathrm{ml}$ proteinase $\mathrm{K}$ at $37^{\circ} \mathrm{C}$ for $20 \mathrm{~min}$. After washing and incubation with equilibration buffer for $5 \mathrm{~min}$, terminal deoxynucleotidyl transferase (TdT) was diluted 1:2.3 (33 $\mu \mathrm{l}$ of TdT enzyme in $77 \mu \mathrm{l}$ of reaction buffer) and incubated on the slides for $1 \mathrm{~h}$ at $37^{\circ} \mathrm{C}$. After applying stop solution for $10 \mathrm{~min}$ and washing, the samples were incubated with anti-digoxigenin peroxidase conjugate at $37^{\circ} \mathrm{C}$ for $30 \mathrm{~min}$. Slides were developed with a 1:50 dilution of diaminobenzidine (3, 3'diaminobenzidine) substrate, counterstained with methyl green, dehydrated, and cover slips were mounted. TUNELpositive cells in tissues were counted in three fields per section at 200 -fold magnification by using light microscopy and the average of the total number of positively stained cells was calculated.

\section{Statistical Analysis}

We used IBM SPSS Statistics 19 (IBM, Armonk, NY) for data analysis. All data are presented as the mean \pm s.d. The amyloid score of each organ and the AI, which is a semi-
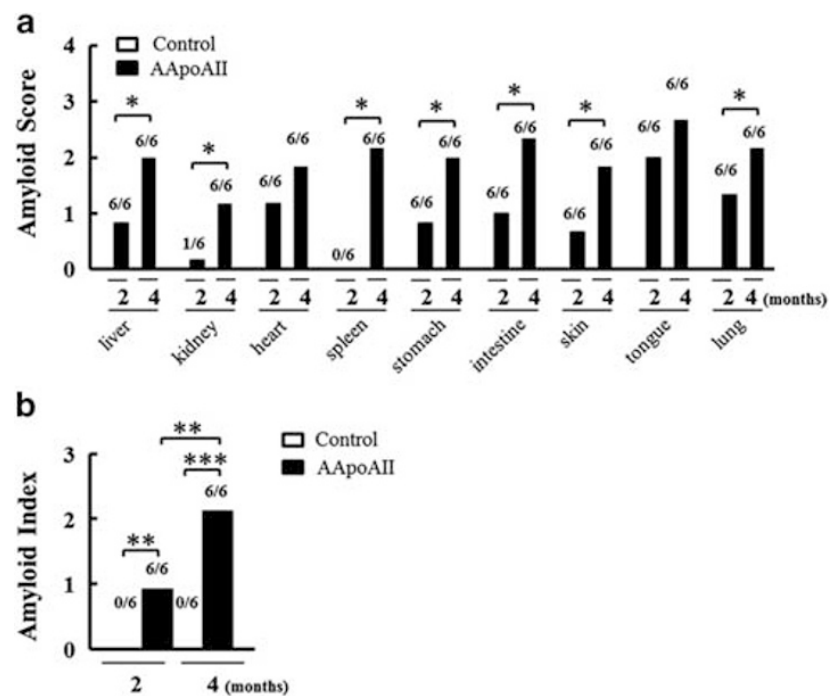

Figure 1 AApoAll amyloid deposition was induced in R1.P1-Apoa2 ${ }^{C}$ mice by injection of AApoAll amyloid fibrils. The extent of amyloid deposition was determined semi-quantitatively in Congo Red-stained sections, using the amyloid score as a parameter, which was graded from zero to four in each organ. Amyloid deposition was assessed in R1.P1-Apoa2 ${ }^{C}$ mice 2 and 4 months after injection of one $\mu \mathrm{g}$ AApoAll amyloid fibrils using Congo Red-stained sections. The amyloid score was determined in different organs (a). The amyloid index represents the average degree of deposition in the seven organs examined (heart, liver, spleen, stomach, intestine, tongue, and skin) (b). Numbers above the columns represent amyloid-positive mice/examined mice. $n=6$ per group. ${ }^{* *} P<0.01$; ${ }^{* * *} P<0.001$

quantitative parameter reflecting the degree of systemic amyloid deposition, are nonlinear. Therefore, significant differences in the values of the amyloid score of each organ and AI were examined among the various groups of mice using the Mann-Whitney $U$-test. One-way ANOVA and Student's $t$-test were used for all data, except AI.

\section{RESULTS}

\section{AApoAll Amyloid Deposits in R1.P1-Apoa2 ${ }^{c}$ Mice}

In this study, we intravenously injected $1 \mu \mathrm{g}$ of AApoAII fibrils into 2-month-old female R1.P1-Apoa $2^{c}$ mice to induce systemic AApoAII deposition. The extent of amyloid deposition was determined semi-quantitatively in Congo Redstained sections, using the amyloid score as a parameter, which was graded from zero to four in each organ. Amyloid deposition in each tissue was determined by the green birefringence in Congo Red-stained sections 2 and 4 months after the injection. AApoAII deposition was confirmed by immunohistochemistry. As Figure 1a illustrates, there were no amyloid deposits in any organ 2 or 4 months after DW injection. However, systemic amyloid deposits were induced by injection of AApoAII fibrils. Immunohistochemical staining for amyloid deposition was positive with antiAApoAII antiserum but negative with anti-AA antiserum (data not shown). The amyloid score of the liver was 0.83 two months after the injection and increased to 2.0 after 
a
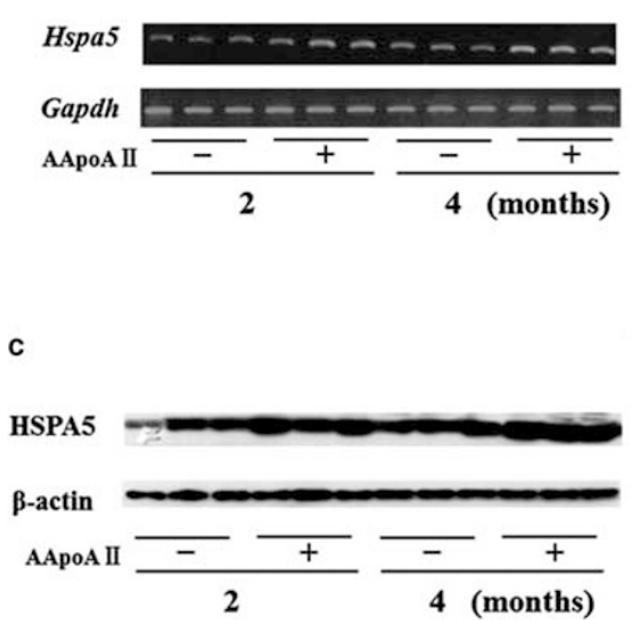
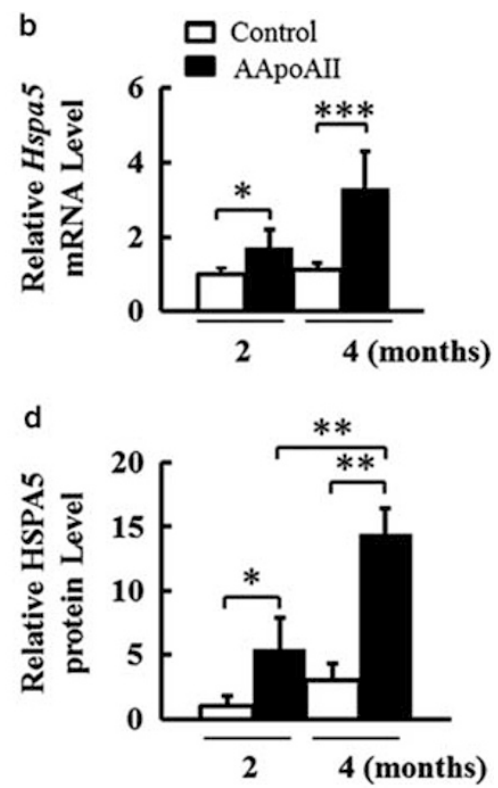

Figure 2 Hspa5 mRNA and HSPA5 protein levels increased with amyloid deposition in the liver. The expression levels of Hspa5 mRNA were determined by reverse transcriptase-PCR (a) and real-time PCR analysis (b). The levels of HSPA5 protein were detected by western blotting (c) and analyzed quantitatively (d). $n=6$ per group. Data are expressed as means \pm s.d. ${ }^{*} P<0.05 ;{ }^{*} P<0.01 ;{ }^{* *} P<0.001$.

4 months. In the kidney, one mouse out of six had amyloid deposits and the amyloid score was 0.17 two months after injection. After 4 months, all six had amyloid deposits and the amyloid score had increased to 1.17. The amyloid score of the heart increased from 1.17 after 2 months to 1.83 after 4 months. The deposition of AApoAII amyloid fibrils increased with age in each organ and the AI, the average degree of deposition of seven organs, increased from 0.92 after 2 months to 2.12 after 4 months (Figure 1b).

\section{HSPA5 Levels Increased in the Liver with AApoAll Amyloid Deposition}

We analyzed the expression of HSPA5, an ER-resident chaperone, in the liver in R1.P1-Apoa2 ${ }^{c}$ mice with or without AApoAII fibril injection. First, we examined the expression of Hspa5 mRNA by RT-PCR. The Hspa 5 mRNA levels were increased in R1.P1-Apoa $2^{c}$ mice 2 and 4 months after injection with AApoAII fibrils compared with control mice (Figure 2a). To obtain quantitative gene expression values, mRNA levels were quantified by real-time RT-PCR. Expression of Hspa5 mRNA was increased significantly in R1.P1Apoa $2^{c}$ mice 2 months after injection of AApoAII fibrils compared with control mice without injection. Furthermore, Hspa 5 mRNA levels were further increased by AApoAII amyloid deposits after 4 months (Figure $2 \mathrm{~b}$ ). We next asked whether the levels of HSPA5 protein were increased in R1.P1Apoa $2^{c}$ mice injected with AApoAII fibrils. Consistent with the mRNA changes, the protein levels of HSPA5 were increased in R1.P1-Apoa2 ${ }^{c}$ mice 2 and 4 months following AApoAII fibril injection compared with age-matched control mice (Figure 2c). HSPA5 protein levels were further elevated by AApoAII amyloidosis deposition after 4 months (Figure 2d). The association of HSPA5 expression with AApoAII amyloid deposition was further analyzed in the liver by immunochemical staining. We did not observe AApoAII amyloid deposits in control mice (Figure $3 \mathrm{a}$ and e) and HSPA5 was undetectable (Figure 3i). Heavy AApoAII amyloid deposits were detected in the extracellular spaces of the liver in R1.P1-Apoa2 ${ }^{c}$ mice 4 months after AApoAII fibril injection (Figure $3 \mathrm{~b}-\mathrm{d}$ and $\mathrm{f}-\mathrm{h}$ ). Hepatocytes in close contact with AApoAII amyloid deposits exhibited positive HSPA5 staining (Figure $3 \mathrm{j}-\mathrm{l}$ ). In contrast, there was no detectable HSPA5 staining in hepatocytes lacking contact with AApoAII amyloid deposits (Figure 3f, h, i, and l).

\section{HSPA5 Levels Increased in the Kidney with AApoAll Amyloid Deposition}

We also analyzed the expression of HSPA5 in the kidney in R1.P1-Apoa2 $2^{c}$ mice with or without injection of $1 \mu \mathrm{g}$ of AApoAII fibrils. Hspa5 mRNA expression levels determined by RT-PCR (Figure $4 \mathrm{a}$ ) and real-time RT-PCR (Figure $4 \mathrm{~b}$ ) were increased in R1.P1-Apoa $2^{c}$ mice 4 months after AApoAII fibril injection compared with age-matched control mice. Four months after AApoAII fibril injection, the expression of Hspa5 mRNA was two times higher in R1.P1$A$ poa $2^{C}$ mice than in control mice (Figure $4 \mathrm{~b}$ ). Next, we analyzed HSPA5 protein levels by western blotting. The protein levels of HSPA5 were 2.8 times higher in control R1.P1-Apoa $2^{c}$ mice after 4 months than in control mice after 2 months. HSPA5 levels were 2.3 times higher in R1.P1Apoa $2^{c}$ mice 4 months after AApoAII fibril injection than in age-matched control mice (Figure $4 \mathrm{c}$ and $\mathrm{d}$ ). Thus, the 

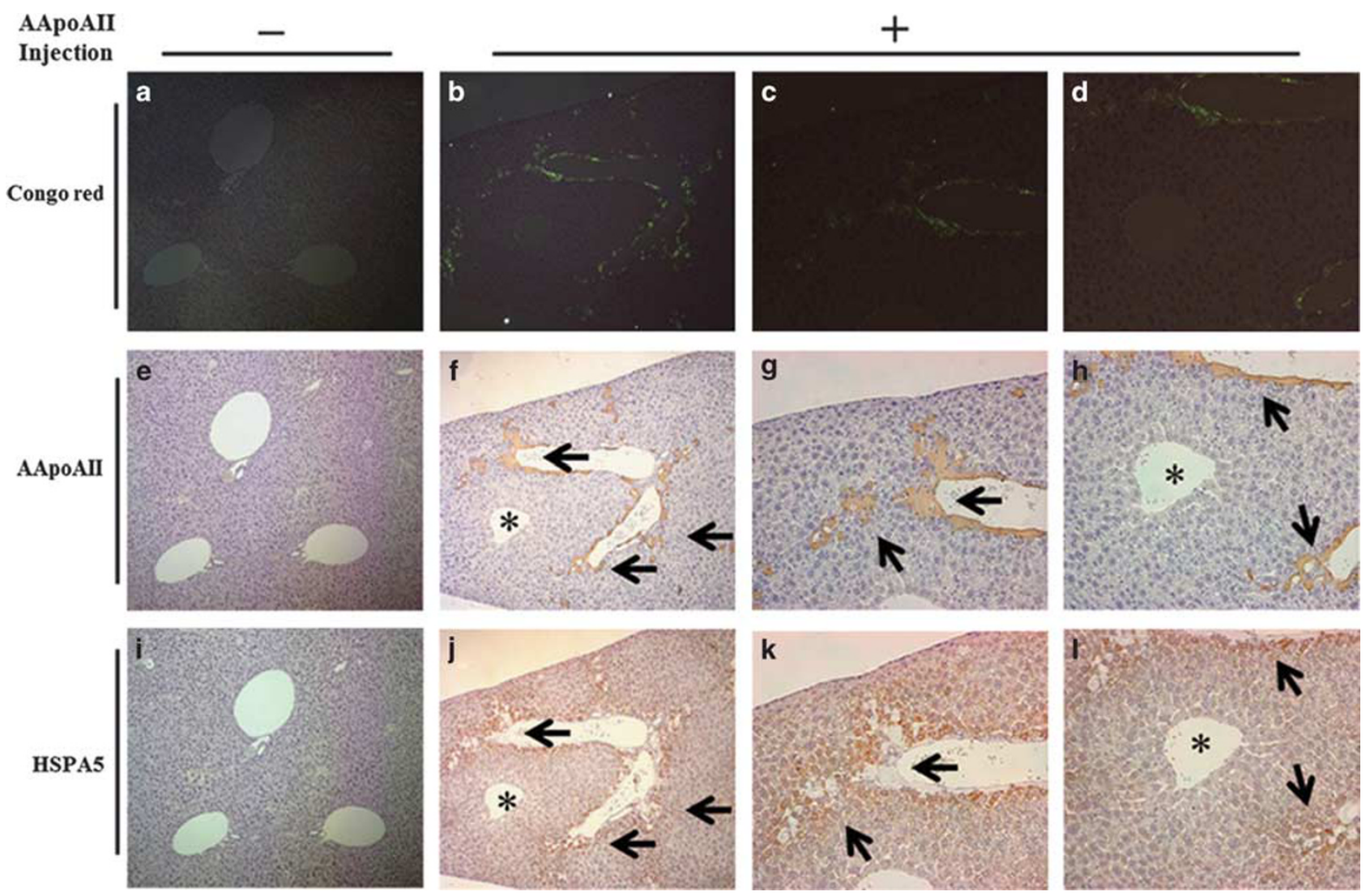

Figure 3 HSPA5 staining was strongly association with amyloid deposition in the liver. Congo Red-stained liver sections in control mice (a) and mice 4 months after injection of AApoAll amyloid fibrils (b-d). Mice with amyloid deposition (b-d; amyloid scores of two) displayed green birefringence under polarizing microscopy. Immunohistochemical staining of AApoAll of control mice (e) and mice (f-h) 4 months after AApoAll amyloid fibril injection. Immunohistochemical staining of HSPA5 in control mice (i) and mice 4 months after AApoAll amyloid fibril injection (j-l). The arrows indicate amyloid deposition and the asterisk shows that no amyloid deposition occurred around the center vein. Magnification: $\times 100$ (a, b, e, f, i, and j). Magnification: $\times 200$ (c, d, $\mathbf{g}, \mathbf{h}, \mathbf{k}$, and $\mathbf{I})$.

protein levels of HSPA5 were elevated after AApoAII amyloid deposition. Consistent with our assessment of mRNA and protein levels, after 4 months immunochemical staining of kidney tissues from control mice without amyloid deposition revealed low-level HSPA5 expression in renal tubules in the medulla nephrica (Figure 5a, d and g), whereas no HSPA5 expression was observed in the cortex (data not shown). Four months after injection of R1.P1-Apoa $2^{c}$ mice with AApoAII fibrils, AApoAII amyloid deposition was found in both the kidney medulla (Figure $5 \mathrm{~b}$ and e) and cortex (Figure $5 \mathrm{c}$ and f). Renal tubular cells around AApoAII amyloid fibrils deposits exhibited increased HSPA5 staining in both the medulla (Figure 5h) and cortex (Figure 5i), compared with age-matched control mice lacking AApoAII amyloid deposition, suggesting a link between HSPA5 expression and AApoAII amyloid deposits.

\section{HSPA5 Levels were Unchanged in Hearts after AApoAll Amyloid Deposition}

AApoAII amyloid deposits in the heart were observed in R1.P1-Apoa ${ }^{c}$ mice after injection (Figure 1a and Figure $6 c$ and d). However, increases in Hspa5 mRNA levels were not detected by RT-PCR (Figure 6a) or real-time RT-PCR (Figure 6b) in R1.P1-Apoa2 ${ }^{C}$ mice 2 and 4 months after injection. As Figure 6c-e illustrate, although heavy AApoAII amyloid deposits were observed in the hearts of R1.P1Apoa $2^{c}$ mice 4 months after AApoAII fibril injection, there was no detectable HSPA5 staining in myocardial cells in contact with AApoAII amyloid deposits.

\section{Increased Expression of ER Stress-Associated Genes in the Liver and Kidney was Associated with Amyloid Deposits}

Based on the above findings, we speculated that ER stress and the UPR system were evoked by AApoAII amyloid deposition in the liver and kidney. We found that the mRNA expression levels of Eif2ak3 and Atf6 were significantly increased in the liver in R1.P1-Apoa2 $2^{c}$ mice 4 months after AApoAII fibril injection compared with age-matched control mice (Figure 7a). Expression of Eif2ak3 mRNA was also significantly increased in the kidneys of mice 4 months after treatment with AApoAII fibrils (Figure 7b). However, there 
a

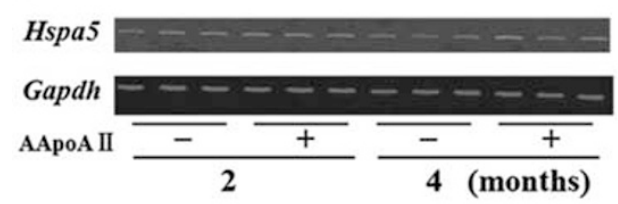

b

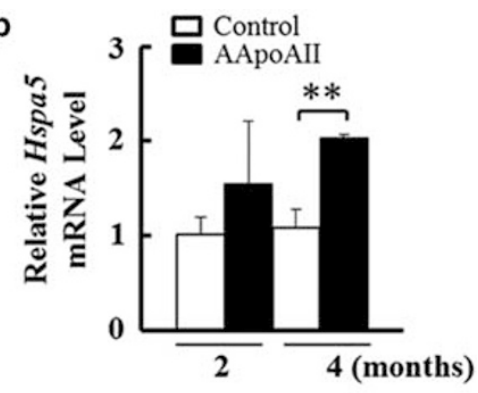

C

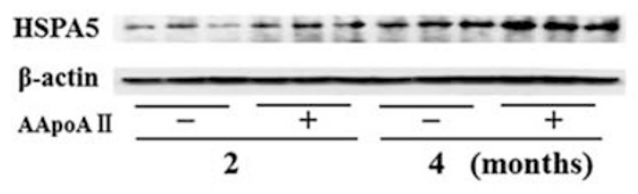

d

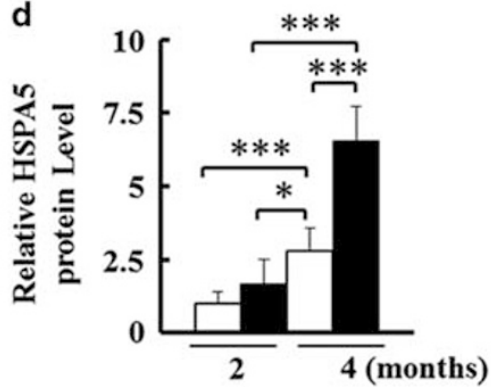

Figure 4 mRNA and protein expression of HSPA5 was increased with amyloid deposition in the kidney. The expression levels of Hspa5 mRNA were determined by reverse transcriptase-PCR (a) and real-time PCR analysis (b). Levels of HSPA5 protein were detected by western blotting (c) and analyzed quantitatively (d). $n=6$ per group. Data are expressed as means \pm s.d. ${ }^{*} P<0.05 ;{ }^{*} P<0.01$.

was no change in the mRNA expression of Ern1 in either the liver (Figure 7a) or the kidney (Figure 7b).

We also analyzed the mRNA expression levels of downstream mediators of Eif2ak3. These included: (1) activating transcription factor 4 (Atf4), (2) DNA-damage inducible transcript 3 (Ddit3) (also known as CCAAT/enhancer-binding homologous protein $(C H O P)$, a critical component of the ER stress-UPR system that induces cell death ${ }^{29,30}$ ), and (3) autophagy protein 5 (Atg5), which is inducible by ER stress. ${ }^{31,32}$ Atf4, Ddit3, and Atg5 were significantly increased in the liver (Figure 7a), and Atf4 and Atg5 were significantly elevated in the kidney (Figure $7 \mathrm{~b}$ ) in mice 4 months after AApoAII fibril injection. The X-box binding protein 1 transcription factor splicing (Xbp1s) is a key transcription factor of the ER stress response. We found that expression of Xbp1s mRNA was significantly increased in the livers (Figure 7a) and the kidneys (Figure 7b) of mice 4 months after treatment with AApoAII fibrils.

Together, these results indicate that extracellular AApoAII amyloid deposition induced ER stress both in the liver and kidney. However, 4 months after injection of AApoAII fibrils, none of the ER stress-associated genes examined here were upregulated in the hearts of treated mice (Figure 7c).

\section{Apoptosis was Increased in Hepatocytes and Renal Tubule Cells after Deposition of AApoAll}

A significant fraction of B-cell leukemia/lymphoma 2 (BCL2) family members including pro-apoptotic BCL2-associated X protein (BAX) and anti-apoptotic BCL2 are important regulators of apoptotic cell death associated with excess ER stress. ${ }^{15}$ We analyzed the expression of pro-apoptotic Bax and anti-apoptotic Bcl2 mRNA by real-time RT-PCR. Four months after AApoAII fibril injection, the expression of pro-apoptotic Bax mRNA was increased significantly both in the livers (Figure 8a) and the kidneys of the treated mice (Figure 8c) compared with control mice. The expression of anti-apoptotic Bcl2 mRNA was unchanged in the livers (Figure 8a) and the kidneys (Figure 8c). Thus, the ratio of $\mathrm{Bax} / \mathrm{Bcl} 2$ increased in the liver (Figure $8 \mathrm{~b}$ ) and the kidney (Figure 8d), with aggravated AApoAII amyloid deposition. The expression of pro-apoptotic Bax mRNA and antiapoptotic $B c l 2$ mRNA was unchanged in the hearts (Figure $8 \mathrm{e}$ ) and the ratio of $B a x / B c l 2$ was unchanged (Figure 8f). We analyzed cell apoptosis by TUNEL assays. TUNEL assays confirmed that the numbers of TUNEL-positive cells were increased in the liver (Figure $9 b$ and c) and the kidney (Figure 9e and f) 4 months after injection with AApoAII fibrils compared with control mice, in which few TUNEL-positive cells were seen in the liver (Figure 9a) and the kidney (Figure 9d). We could not find TUNEL-positive cells in cardiac tissue, either in control mice or in mice with amyloid deposition 4 months after injection of AApoAII amyloid fibrils (Figure 9g, h and i).

\section{ER Stress Responses in Aged Mice with Spontaneous Amyloid Deposition}

As Supplementary Figure S1a illustrates, there were no amyloid deposits in any organ in young 4-month-old control mice or in aged, 15-month-old control mice that had been maintained in another room in which amyloidosis had not 

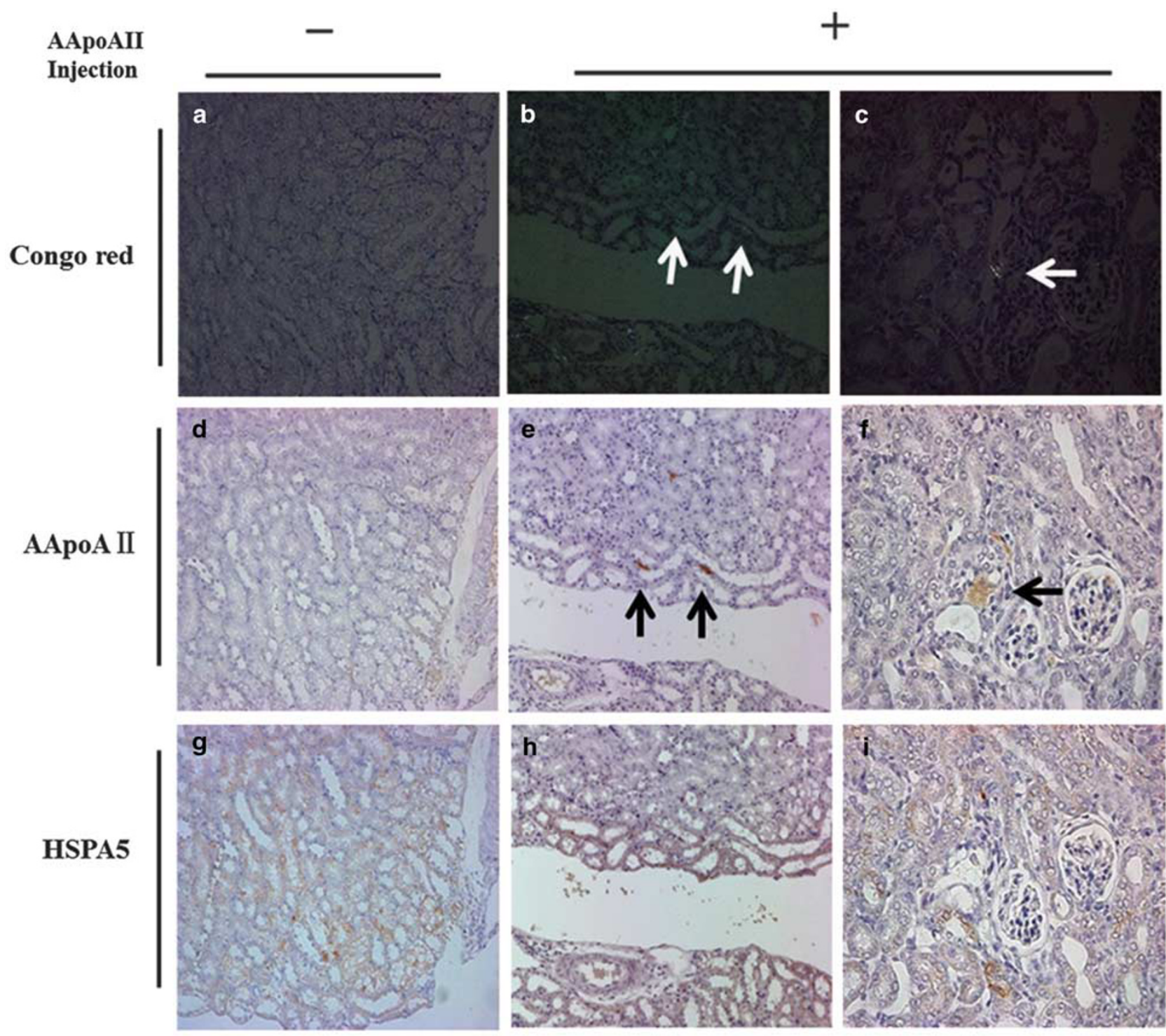

Figure 5 Increased intensity of immunohistochemical staining of HSPA5 was associated with amyloid deposition in the kidney. Congo Red-stained sections displayed green birefringence in control mice (a) and experimental mice 4 months after AApoAll amyloid fibril injection (b and c).

Immunohistochemical staining of AApoAll in control mice (d) and experimental mice (e and f) 4 months after AApoAll amyloid fibril injection. Immunohistochemical staining of HSPA5 in control mice (g) and experimental mice 4 months after AApoAll amyloid fibril injection (h and $\mathbf{i})$. Amyloid scores of the kidneys were one and two in mice (b and $\mathbf{c}$, respectively). The arrows indicate amyloid deposition. Magnification: $\times 200$.

been induced and observed. However, spontaneous systemic amyloid deposits were observed in aged, 9- and 13-monthold mice that had not been injected with amyloid fibrils but were instead kept in the same room where injection of seeds had been done. The AI, the average degree of systemic amyloid deposition, was 2.33 (Supplementary Figure S1a and b).

Hspa5 mRNA expression levels were determined in old mice with spontaneous amyloid deposition in the liver, kidney and heart (Supplementary Figure S2). The Hspa5 mRNA levels were increased in the livers of old mice with or without amyloid deposition compared with young mice. However, no difference was observed between amyloid-negative and -positive mice. The Hspa5 mRNA levels were significantly increased only in the kidneys of old amyloid-positive mice compared with young and aged, 15-month-old control mice. In the heart, the Hspa5 mRNA levels were increased in both the amyloid-negative and -positive old mice compared with young mice, but amyloid deposition did not induce further Hspa5 expression.

We assessed ER stress and the UPR in mice with spontaneous amyloid deposition in the liver, kidney and heart. We found that the mRNA expression levels of Eif2ak3, Atf6 and Ern1 were significantly increased in the livers of R1.P1Apoa $2^{c}$ mice with spontaneous amyloid deposition compared with young mice, but only Ern1 significantly increased 
a

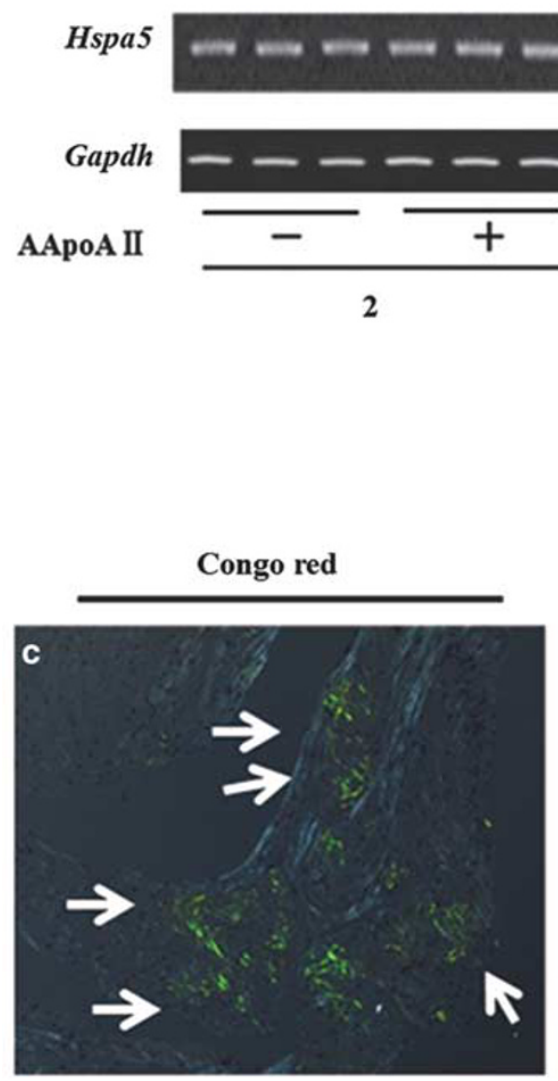

b
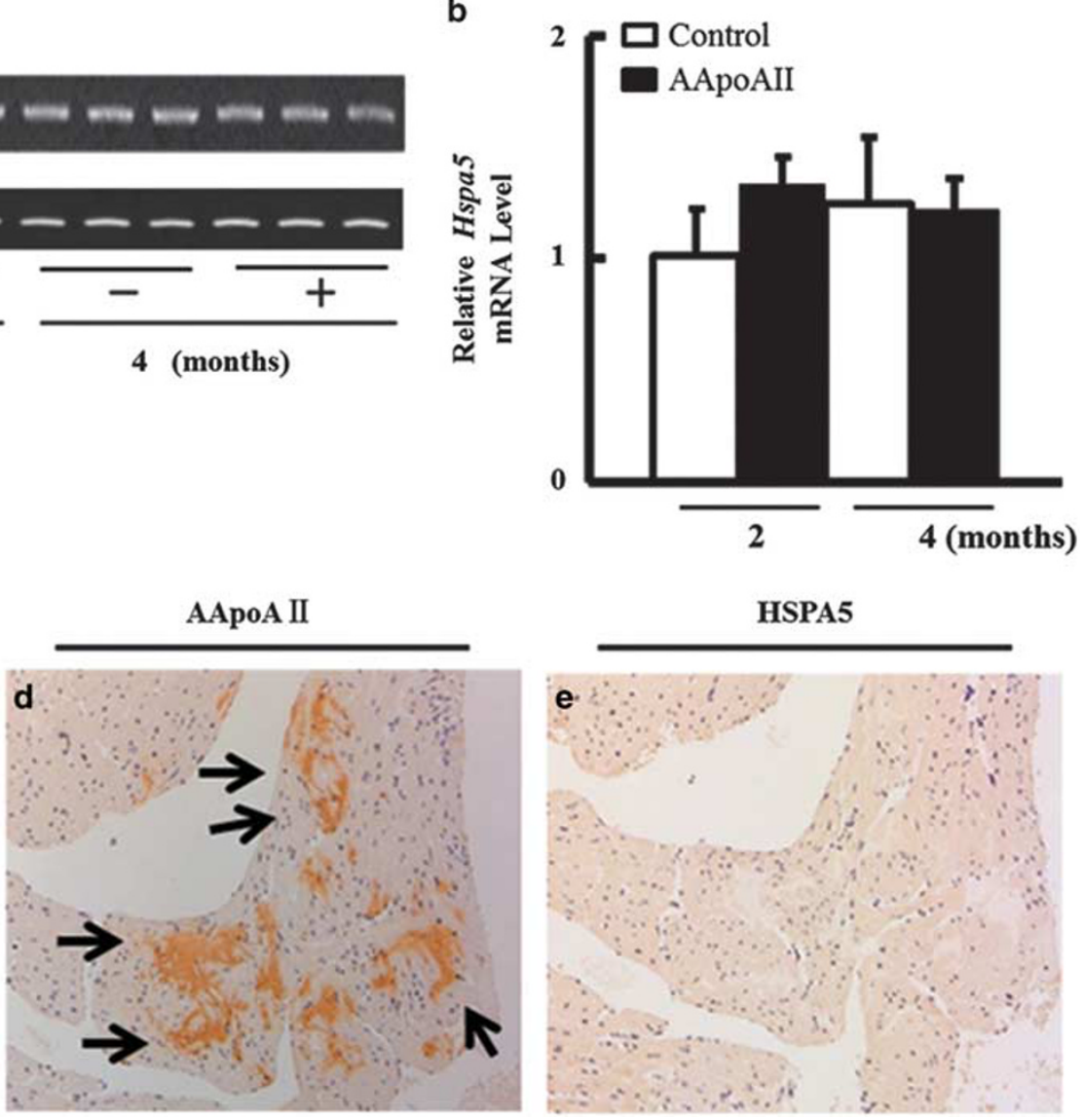

HSPA5

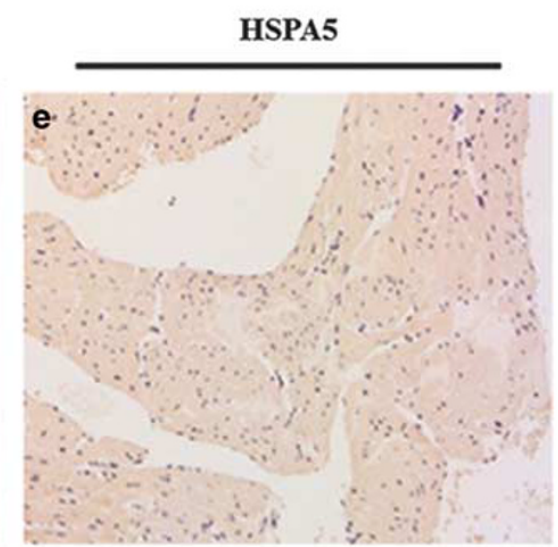

Figure 6 mRNA and protein expression levels of HSPA5 did not change with amyloid deposition in the heart. The expression of Hspa5 mRNA was determined by reverse transcriptase-PCR (a) and real-time PCR analysis (b). Congo Red-stained (c) and immunohistochemical staining of AApoAll (d) and HSPA5 (e) in mice 4 months after AApoAll amyloid fibril injection. The arrows indicate amyloid deposition. The amyloid score of the heart was three. Magnification: $\times 200 . n=6$ per group.

relative to aged, 15-month-old control mice (Supplementary Figure S3a). Expression of Eif2ak3, Atf6, Ern1, Ddit3, and Atg5 mRNAs was significantly increased in the kidneys of mice with spontaneous amyloidosis, but only Ern1 and Atg5 mRNAs significantly increased relative to aged control mice (Supplementary Figure S3b). In the heart, Atf6, Ern1, $X b p 1$, and Ddit3 were significantly increased in mice with spontaneous amyloid deposition compared with young mice, but there was no significant difference compared with aged amyloidosis-negative control mice (Supplementary Figure S3c).

\section{DISCUSSION}

In this study, we selected specific organs (the liver, kidney and heart) for our investigation for the following reasons: The liver has the most severe AApoAII amyloid deposition and synthesizes ApoA-II. The kidney also has severe AApoAII deposition that leads to contraction in mice. Finally, the heart shows severe amyloid deposition, leading to cardiac failure in human amyloid immunoglobulin light chain (AL) amyloidosis and FAP.
The present data clearly demonstrate a connection between ER stress and the deposition of extracellular AApoAII amyloid. We observed that AApoAII amyloid had deposited 2 months after AApoAII fibril injection, and that it was more pronounced after 4 months. Increased mRNA and protein expression of the ER-resident chaperon HSPA5 was observed in the liver and kidney, associated with AApoAII amyloid deposition. Interestingly, immunohistochemical staining showed that hepatocytes in close contact with AApoAII amyloid deposition exhibited strong HSPA5 staining. In contrast, there was no detectable HSPA5 staining in hepatocytes lacking contact with AApoAII amyloid deposits, suggesting a cause-and-effect relationship. Using immunohistochemical staining, we also found increased HSPA5 was associated with AApoAII amyloid deposits in the kidney. However, HSPA5 staining was detected in renal tubular cells surrounding but lacking contact with AApoAII amyloid deposits in both the medulla and cortex of the kidney. It is unclear how AApoAII amyloid deposition induced HSPA5 expression in cells lacking contact with the fibrillar deposition in the kidney. It is possible that oligomeric or 

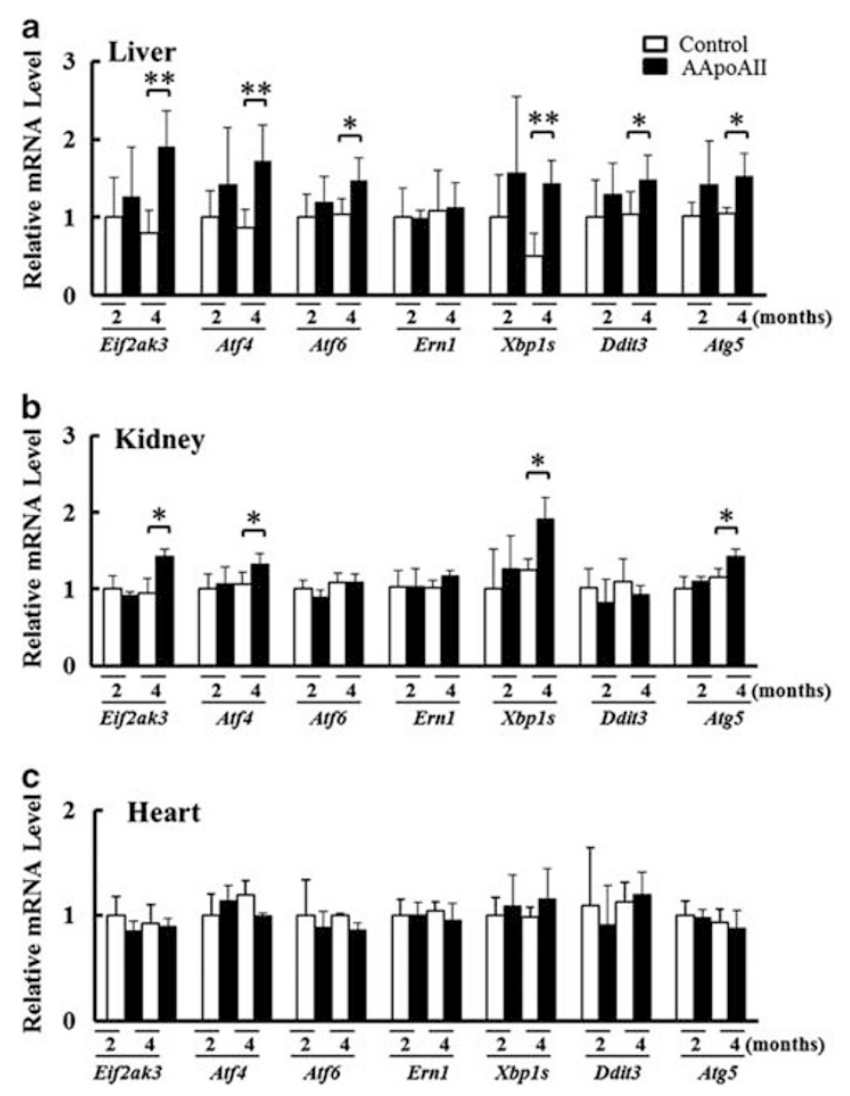

Figure 7 mRNA expression of endoplasmic reticulum (ER) stressassociated genes increased in the liver and kidney with amyloid deposits but not in the heart. ER stress-associated mRNA expression was assessed by real-time PCR analysis in the liver (a), kidney (b) and heart (c). $n=6$ per group. Data are expressed as the means \pm s.d. ${ }^{*} P<0.05 ;{ }^{* *} P<0.01$.

nonfibrillar AApoAII around the cells might induce an HSPA5 response.

HSPA5 belongs to the HSP70 family of molecular chaperones. ${ }^{33}$ Expression of HSPs is upregulated by the presence of misfolded proteins within the ER, leading to reduced aggregation. ${ }^{14,34}$ HSPA5 has a dual role in the ER, functioning as a resident chaperone regulating protein folding and preventing aggregation while also regulating signaling within the UPR. As a chaperone, HSPA5 recognizes and binds hydrophobic residues in the unfolded regions of proteins $^{35}$ and works with other ER molecular chaperones that process unfolded protein substrates. ${ }^{36}$ HSPA5 and other UPR markers are increased in the neurons of AD patients versus the non-demented controlled individuals. ${ }^{37}$ In vitro studies have demonstrated that HSPA 5 is induced by $\mathrm{A} \beta$ fibrils in neuronal cells. ${ }^{38,39}$ Moreover, upregulation of HSPA5 was believed to protect against $\mathrm{A} \beta$ toxicity. ${ }^{40}$ HSPA5 was detected with extracellular TTR deposition, whereas HSPA5 was negative without deposition in FAP model mice. ${ }^{24}$

HSPA5 is a key mediator of the UPR, being a 'sensor' of ER stress. ${ }^{41}$ HSPA5 functions as a master regulator of the UPR by binding to and preventing the activation of all three proximal stress sensors (under nonstressed conditions): EIF2AK3, ERN1, and ATF6. Under conditions of ER stress, the release of HSPA5 results in the activation of EIF2AK3, leading to phosphorylation of the PERK eukaryotic translation inhibition factor $2 \alpha$ (EIF2A), reducing global mRNA translation, while favoring the translation of selected mRNAs, such as Atf4 mRNA. ATF4 activates the transcription of UPR target genes encoding factors involved in restoring ER homeostasis via amino acid biosynthesis, antioxidative stress responses, autophagy, and apoptosis. Dissociation of HSPA5 from ATF6 uncovers a Golgi localization sequence and triggers translocation of ATF6 to the Golgi where it is cleaved by site- 1 and site- 2 proteases. ${ }^{42}$ The N-terminal cleavage product of ATF6 translocates to the nucleus and regulates gene expressions. Target genes of ATF6 are mainly adaptive proteins, such as HSPA5. ATF6 also upregulates expression of the pro-survival transcription factor XBP $1 .{ }^{43}$ Under ER stress, activated ERN1 removes a 26-nucleotide intron from Xbp1 mRNA. ${ }^{43}$ The Xbp1 splicing (Xbp1s) mRNA encodes a potent transcription factor that translocates to the nucleus and activates the expression of genes involved in the re-establishment of protein folding or in the degradation of unfolded proteins. ${ }^{44}$ Under severe ER stress, ATF4, XBP1s, and ATF6 can increase the expression of the pro-apoptotic transcription factor DDIT3. ${ }^{19}$

We found that expression Eif2ak3, Atf6, Atf4, Xbp1s, Ddit3, and Atg 5 mRNAs was significantly increased in the livers showing AApoAII deposition. The expression of Eif2ak3, Atf4, Xbp1s, and Atg5 mRNAs was significantly increased in kidneys in which AApoAII was deposited. These results indicate that the UPR might be important for maintenance of cellular ER function with extracellular AApoAII amyloid deposition. Our results are in agreement with recent findings that ER stress is related to extracellular amyloidosis. ${ }^{21,22,24}$ Although it is unclear how extracellular $\mathrm{A} \beta$ sends signals to the ER, it has been shown that extracellular $\mathrm{A} \beta$ can induce the UPR. ${ }^{19,38,39}$ AApoAII amyloid fibrils deposit in extracellular spaces, but it remains unclear whether monomers, oligomers, or fibrils accumulate intracellularly. HSPA5 does not localize exclusively to the ER and under specific circumstances, such as development of drug resistance and cell transformation, it has been shown to relocate to the cell membrane..$^{45}$ During aging, there is a shift in the balance between the protective/adaptive responses of the UPR and pro-apoptotic signaling. Thus, the protective arm decreases in activity and the apoptotic arm becomes more robust with aging. ${ }^{46}$ HSPA5 expression levels are significantly reduced in several species with age. ${ }^{46,47}$ The loss of HSPA5 function could be a predisposing factor for many neurodegenerative disorders associated with age, including $\mathrm{AD}^{48}$ We assessed the UPR in old mice with and without spontaneous amyloid deposition. Hspa5 mRNA levels were elevated in old mice without amyloid deposits in the liver or heart. Moreover, spontaneous amyloid deposition did not 

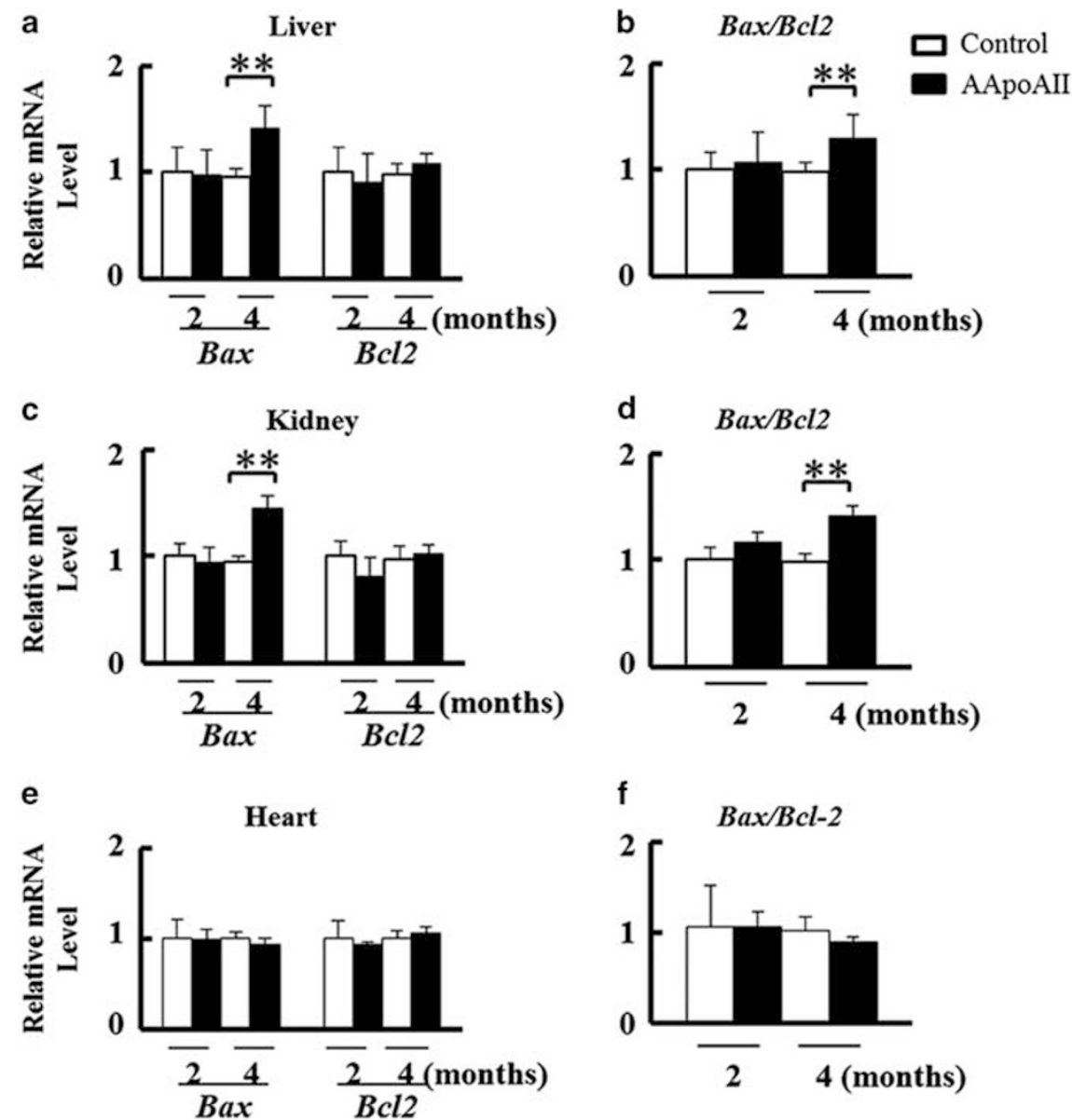

Figure 8 Apoptotic genes in the liver and kidney increased expression in R1.P1-Apoa2 ${ }^{C}$ mice 4 months after AApoAll fibril injection. Levels of Bax and $B C / 2$ mRNAs were detected by real-time reverse transcriptase-PCR analysis of the liver (a), kidney (c) and heart (e). The ratio of $B a x / B c / 2$ was increased in the liver (b) and kidney (d), but not in the heart (f). $n=6$ per group. Data are expressed as means \pm s.d. ${ }^{*} P<0.05$; ${ }^{* *} P<0.01$.

induce further induction of Hspa5 expression in the liver or heart. HSPA5 might be induced adaptively to maintain homeostasis of disturbed protein metabolism associated with aging. The lack of further induction of HSPA5 might be associated with acceleration of spontaneous senile AApoAII amyloidosis in the mouse liver and heart. Amyloid deposition increased Hspa5 expression significantly in the kidney.

More recently, it was shown that the UPR leads to the transcriptional upregulation of a number of autophagy-related genes essential for both the induction and construction of the autophagy machinery during ER stress. ${ }^{31,32}$ Autophagy upregulation during ER stress is an essential pro-survival response and is required for the removal of unfolded proteins, protein aggregates, and damaged organelles. Activation of these processes relieves the stress and reinstates homeostasis of the ER. ${ }^{49}$ In fact, a recent study suggests that autophagy is a major degradation pathway following UPR activation in neuronal cells, highlighting a connection between UPR activation and autophagic pathology in $\mathrm{AD} .{ }^{50}$ Autophagy deficiency leads to intracellular $\mathrm{A} \beta$ accumulation. Moreover, autophagy deficiency induces neurodegeneration ${ }^{51}$ and $\mathrm{A} \beta$ amyloid deposition intensifies autophagy-induced neurodegenerative processes. ${ }^{52}$ We also found that expression of Atg5 mRNA was significantly increased in the liver and kidney with extracellular AApoAII amyloid deposition.

When protein aggregation is persistent and the stress cannot be resolved, signaling switches from pro-survival to pro-apoptosis. ${ }^{15}$ ER stress conditions have been observed in numerous diseases including AD, Huntington disease, as well as type 2 diabetes, indicating that ER stress-induced apoptosis is an important factor in pathophysiology. The mRNA levels for the pro-apoptotic transcription factor Ddit3 increased in the liver with AApoAII amyloid deposition. We speculated that apoptosis is increased by AApoAII amyloid deposition in the liver and/or the kidney. The BCL2 family can be either pro-apoptotic (eg, BAX and BAK) or anti-apoptotic (eg, BCL2 and BCL-xL). In resting conditions, pro-apoptotic BAX and BAK are kept inactive by interaction with BCL2. Severe ER stress leads to the antiapoptotic BCL2 being displaced from the pro-apoptotic 

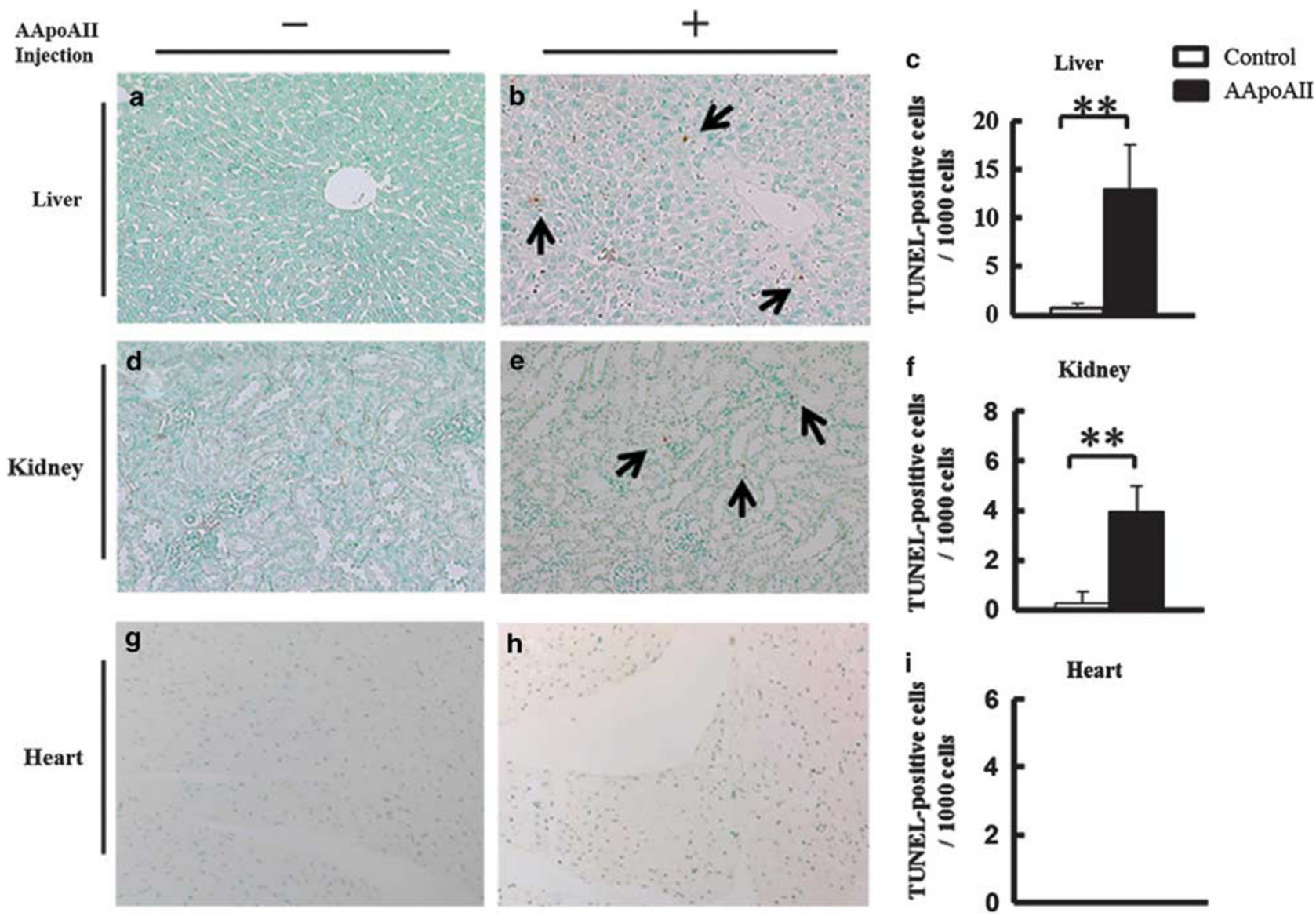

Figure 9 Apoptosis-positive cells in the liver and kidney were increased in R1.P1-Apoa2 ${ }^{C}$ mice 4 months after AApoAll fibril injection. TUNEL-positive cells in the liver were detected in control mice (a) and mice 4 months after AApoAll amyloid fibril injection (b). Numbers of TUNEL-positive cells per 1000 cultured cells in the liver (c). TUNEL-positive cells in the kidney were detected in control mice (d) and mice 4 months after AApoAll amyloid fibril injection (e). Numbers of TUNEL-positive cells per 1000 cultured cells in the kidney (f). No TUNEL-positive cells in the heart were detected in control mice ( $\mathbf{g}$ and $\mathbf{i}$ ) or in mice 4 months after AApoAll amyloid fibril injection ( $\mathbf{h}$ and $\mathbf{i})$. Magnification: $\times 200 . n=6$ per group. Data are expressed as means \pm s.d. ${ }^{*} P<0.05 ;{ }^{* *} P<0.01$.

proteins, leading to activation. Thus, the balance between pro-apoptotic and anti-apoptotic proteins determines apoptotic cell death. Overexpression of BCL2, or deficiency of BAX and BAK, can protect against lethal ER stress. ${ }^{53,54} \mathrm{We}$ investigated whether apoptosis was involved in AApoAII amyloid deposition. Our data showed that the ratio of $B a x / B c l 2$ was increased and TUNEL-positive cells were enhanced in the liver and kidney, with marked deposition of AApoAII amyloid.

In R1.P1-Apoa $2^{c}$ and SAMP1 mice, severe amyloid deposition associated with aging caused enlargement of the liver and heart, contracted the kidney and shortened the life span about 30\%. ${ }^{55,56}$ AApoAII deposition might decrease Apoa 2 mRNA expression in the liver. ${ }^{57}$ However, functional impairments in the liver, kidney and heart associated with AApoAII amyloid deposition were not examined in detail and it is not clear how the UPR and ER stress contribute to maintaining and disrupting cellular functions.

It is interesting that UPR and ER stress responses in the liver and kidney differed from that in the heart. The differences could be explained by the organ-specific structure of amyloid fibrils and organ-specific cell responses to amyloid deposition. We do not currently have evidence that AApoAII amyloid deposits among the organs differ in their structures, including the constituents of the fibrillar proteins and surrounding co-deposited molecules. However, further experiments will be planned to study organ-specific structures. There might be common adaptive and apoptotic URP and ER stress response systems in the hepatic cells in the liver, ${ }^{58}$ glomerular and tubulointerstitial cells in the kidney ${ }^{59}$ and cardio muscular cells in the heart ${ }^{60}$ in the pathogenesis of various diseases. No studies have assessed different UPR and ER responses among tissues. It has been reported that amyloid deposits in the heart induce heart failure in systemic AL amyloidosis. ${ }^{61}$ TTR deposits in the peripheral nerves and the intestine induce ER stress in systemic TTR amyloidosis, ${ }^{62}$ but the mechanism of tissue specificity is not known.

In conclusion, our study indicates that ER stress responses were induced by extracellular AApoAII amyloid deposition. The data demonstrate that the ER resident chaperon HSPA5 
was upregulated and the UPR was induced in hepatocytes and renal cells in response to aggregated extracellular AApoAII amyloid deposits. Apoptosis of hepatocytes and renal cells was also induced by prolonged ER stress. Much remains to be learned about organ-specific UPR and the beneficial and/or deleterious effects of upregulated UPR associated with amyloid deposition in cells and organs. Elucidation of the underlying mechanisms will guide the development of preventive and therapeutic procedures for amyloidosis.

Supplementary Information accompanies the paper on the Laboratory Investigation website (http://www.laboratoryinvestigation.org)

\section{ACKNOWLEDGMENTS}

This work was supported by Grants-in-Aid for Scientific Research (B) 23390093 and 26293084, Science Research on Priority Areas 22020015, and Challenging Exploratory Research (23659150) from the Ministry of Education, Culture, Sports, Science, and Technology of Japan, and by grants from the Intractable Disease Division, the Ministry of Health, Labor, and Welfare to the Research Committees for Amyloidosis. We also thank Dr K Matsumoto at the Division of Laboratory Animal Research, Shinshu University Graduate School of Medicine, for raising mice.

\section{DISCLOSURE/CONFLICT OF INTEREST}

The authors declare no conflict of interest.

1. Sipe JD, Cohen AS. Review: history of the amyloid fibril. J Struct Biol 2000;130:88-98.

2. Sipe JD, Benson MD, Buxbaum JN, et al. Amyloid fibril protein nomenclature: 2012 recommendations from the Nomenclature Committee of the International Society of Amyloidosis. Amyloid 2012; 19:167-170.

3. Benson MD, James S, Scott K, et al. Leukocyte chemotactic factor 2: A novel renal amyloid protein. Kidney Int 2008;74:218-222.

4. Yonezu T, Higuchi K, Tsunasawa S, et al. High homology is present in the primary structures between murine senile amyloid protein (ASSAM) and human apolipoprotein A-II. FEBS Lett 1986;203:149-152.

5. Higuchi K, Yonezu T, Kogishi K, et al. Purification and characterization of a senile amyloid-related antigenic substance (apoSASSAM) from mouse serum. apoSASSAM is an apoA-II apolipoprotein of mouse high density lipoproteins. J Biol Chem 1986;261:12834-12840.

6. Higuchi K, Kitagawa K, Naiki H, et al. Polymorphism of apolipoprotein A-II (apoA-II) among inbred strains of mice. Relationship between the molecular type of apoA-II and mouse senile amyloidosis. Biochem J 1991;279:427-433.

7. Kitagawa K, Wang J, Mastushita T, et al. Polymorphisms of mouse apolipoprotein A-II: seven alleles found among 41 inbred strains of mice. Amyloid 2003;10:207-214.

8. Higuchi $\mathrm{K}$, Naiki $\mathrm{H}$, Kitagawa $\mathrm{K}$, et al. Apolipoprotein A-II gene and development of amyloidosis and senescence in a congenic strain of mice carrying amyloidogenic ApoA-II. Lab Invest 1995;72:75-82.

9. Higuchi $\mathrm{K}$, Kitado $\mathrm{H}$, Kitagawa $\mathrm{K}$, et al. Development of congenic strains of mice carrying amyloidogenic apolipoprotein A-II (Apoa2c). Apoa2c reduces the plasma level and the size of high density lipoprotein. FEBS Lett 1993;317:207-210.

10. Higuchi K, Kogishi K, Wang J, et al. Fibrilization in mouse senile amyloidosis is fibril conformation-dependent. Lab Invest 1998;78: $1535-1542$.

11. Xing $Y$, Nakamura $A$, Korenaga $T$, et al. Induction of protein conformational change in mouse senile amyloidosis. J Biol Chem 2002; 277:33164-33169.

12. Xing $Y$, Nakamura $A$, Chiba $T$, et al. Transmission of mouse senile amyloidosis. Lab Invest 2001;81:493-499.

13. Korenaga T, Yan J, Sawashita J, et al. Transmission of amyloidosis in offspring of mice with AApoAll amyloidosis. Am J Pathol 2006;168: 898-906.
14. Rao RV, Ellerby HM, Bredesen DE. Coupling endoplasmic reticulum stress to the cell death program. Cell Death Differ 2004;11:372-380.

15. Szegezdi E, Logue SE, Gorman AM, et al. Mediators of endoplasmic reticulum stress-induced apoptosis. EMBO Rep 2006;7:880-885.

16. Imaizumi K, Miyoshi K, Katayama $\mathrm{T}$, et al. The unfolded protein response and Alzheimer's disease. Biochim Biophys Acta 2001;1536: 85-96.

17. Doyle KM, Kennedy D, Gorman AM, et al. Unfolded proteins and endoplasmic reticulum stress in neurodegenerative disorders. J Cell Mol Med 2011;15:2025-2039.

18. Back SH, Kaufman RJ. Endoplasmic reticulum stress and type 2 diabetes. Annu Rev Biochem 2012;81:767-793.

19. Viana RJ, Nunes AF, Rodrigues CM. Endoplasmic reticulum enrollment in Alzheimer's disease. Mol Neurobiol 2012;46:522-534.

20. Flamment $M$, Foufelle $F$. Endoplasmic reticulum stress: from physiology to pathogenesis of type 2 diabetes. Med Sci (Paris) 2013; 29:756-764.

21. Nakagawa $\mathrm{T}$, Zhu $\mathrm{H}$, Morishima $\mathrm{N}$, et al. Caspase-12 mediates endoplasmic-reticulum-specific apoptosis and cytotoxicity by amyloid-beta. Nature 2000;403:98-103.

22. Pereira C, Ferreiro E, Cardoso SM, et al. Cell degeneration induced by amyloid-beta peptides: implications for Alzheimer's disease. J Mol Neurosci 2004;23:97-104.

23. Casas S, Gomis R, Gribble FM, et al. Impairment of the ubiquitinproteasome pathway is a downstream endoplasmic reticulum stress response induced by extracellular human islet amyloid polypeptide and contributes to pancreatic beta-cell apoptosis. Diabetes 2007;56: 2284-2294.

24. Teixeira PF, Cerca F, Santos SD, et al. Endoplasmic reticulum stress associated with extracellular aggregates. Evidence from transthyretin deposition in familial amyloid polyneuropathy. J Biol Chem 2006;281:21998-22003.

25. Pras $M$, Schubert $M$, Zucker-Franklin $D$, et al. The characterization of soluble amyloid prepared in water. J Clin Invest 1968;47:924-933.

26. Pras $M$, Zucker-Franklin D, Rimon A, et al. Physical, chemical, and ultrastructural studies of water-soluble human amyloid fibrils. Comparative analyses of nine amyloid preparations. J Exp Med 1969;130:777-796.

27. Naiki H, Higuchi K, Hosokawa M, et al. Fluorometric determination of amyloid fibrils in vitro using the fluorescent dye, thioflavin T1. Anal Biochem 1989;177:244-249.

28. Higuchi K, Matsumura A, Honma A, et al. Systemic senile amyloid in senescence-accelerated mice. A unique fibril protein demonstrated in tissues from various organs by the unlabeled immunoperoxidase method. Lab Invest 1983;48:231-240.

29. Marciniak SJ, Yun CY, Oyadomari S, et al. CHOP induces death by promoting protein synthesis and oxidation in the stressed endoplasmic reticulum. Genes Dev 2004;18:3066-3077.

30. Novoa I, Zhang $\mathrm{Y}$, Zeng $\mathrm{H}$, et al. Stress-induced gene expression requires programmed recovery from translational repression. EMBO J 2003;22:1180-1187.

31. He C, Klionsky DJ. Regulation mechanisms and signaling pathways of autophagy. Annu Rev Genet 2009;43:67-93.

32. Hoyer-Hansen $M$, Jaattela $M$. Connecting endoplasmic reticulum stress to autophagy by unfolded protein response and calcium. Cell Death Differ 2007;14:1576-1582.

33. Kampinga $\mathrm{HH}$, Hageman J, Vos $\mathrm{MJ}$, et al. Guidelines for the nomenclature of the human heat shock proteins. Cell Stress Chaperones 2009;14:105-111.

34. McClellan AJ, Tam S, Kaganovich D, et al. Protein quality control: chaperones culling corrupt conformations. Nat Cell Biol 2005;7: 736-741.

35. Hendershot L, Wei J, Gaut J, et al. Inhibition of immunoglobulin folding and secretion by dominant negative BiP ATPase mutants. Proc Natl Acad Sci USA 1996:93:5269-5274.

36. Ni M, Lee AS. ER chaperones in mammalian development and human diseases. FEBS Lett 2007;581:3641-3651.

37. Hoozemans JJ, Veerhuis R, Van Haastert ES, et al. The unfolded protein response is activated in Alzheimer's disease. Acta Neuropathol 2005; 110:165-172.

38. Ferreiro $E$, Resende $R$, Costa $R$, et al. An endoplasmic-reticulum-specific apoptotic pathway is involved in prion and amyloid-beta peptides neurotoxicity. Neurobiol Dis 2006;23:669-678. 
39. Lee do $\mathrm{Y}$, Lee KS, Lee $\mathrm{HJ}$, et al. Activation of PERK signaling attenuates Abeta-mediated ER stress. PloS One 2010;5:e10489.

40. Yu Z, Luo H, Fu W, et al. The endoplasmic reticulum stress-responsive protein GRP78 protects neurons against excitotoxicity and apoptosis: suppression of oxidative stress and stabilization of calcium homeostasis. Exp Neurol 1999;155:302-314.

41. Lee AS. The ER chaperone and signaling regulator GRP78/BiP as a monitor of endoplasmic reticulum stress. Methods 2005;35:373-381.

42. Haze $\mathrm{K}$, Yoshida $\mathrm{H}$, Yanagi $\mathrm{H}$, et al. Mammalian transcription factor ATF6 is synthesized as a transmembrane protein and activated by proteolysis in response to endoplasmic reticulum stress. Mol Biol Cell 1999;10:3787-3799.

43. Yoshida H, Matsui T, Yamamoto A, et al. XBP1 mRNA is induced by ATF6 and spliced by IRE1 in response to ER stress to produce a highly active transcription factor. Cell 2001;107:881-891.

44. Lee AH, Iwakoshi NN, Glimcher LH. XBP-1 regulates a subset of endoplasmic reticulum resident chaperone genes in the unfolded protein response. Mol Cell Biol 2003:23:7448-7459.

45. Delpino A, Castelli M. The $78 \mathrm{kDa}$ glucose-regulated protein (GRP78/ BIP) is expressed on the cell membrane, is released into cell culture medium and is also present in human peripheral circulation. Biosci Rep 2002;22:407-420.

46. Naidoo N, Ferber M, Master $M$, et al. Aging impairs the unfolded protein response to sleep deprivation and leads to proapoptotic signaling. J Neurosci 2008;28:6539-6548.

47. Paz Gavilan M, Vela J, Castano A, et al. Cellular environment facilitates protein accumulation in aged rat hippocampus. Neurobiol Aging 2006;27:973-982.

48. Gorbatyuk MS, Gorbatyuk OS. The molecular chaperone GRP78/BiP as a therapeutic target for neurodegenerative disorders: a mini review. J Genet Syndr Gene Ther 2013:4:128.

49. Kroemer G, Marino G, Levine B. Autophagy and the integrated stress response. Mol Cell 2010;40:280-293.

50. Nijholt DA, de Graaf TR, van Haastert ES, et al. Endoplasmic reticulum stress activates autophagy but not the proteasome in neuronal cells: implications for Alzheimer's disease. Cell Death Differ 2011;18:1071-1081.
51. Inoue K, Rispoli J, Kaphzan $\mathrm{H}$, et al. Macroautophagy deficiency mediates age-dependent neurodegeneration through a phospho-tau pathway. Mol Neurodegener 2012;7:48.

52. Nilsson $\mathrm{P}$, Loganathan $\mathrm{K}$, Sekiguchi $\mathrm{M}$, et al. Abeta secretion and plaque formation depend on autophagy. Cell Rep 2013;5:61-69.

53. Distelhorst CW, McCormick TS. BCl-2 acts subsequent to and independent of $\mathrm{Ca} 2+$ fluxes to inhibit apoptosis in thapsigarginand glucocorticoid-treated mouse lymphoma cells. Cell Calcium 1996;19:473-483.

54. Wei MC, Zong WX, Cheng EH, et al. Proapoptotic BAX and BAK: a requisite gateway to mitochondrial dysfunction and death. Science 2001;292:727-730.

55. Higuchi K, Wang J, Kitagawa K, et al. Accelerated senile amyloidosis induced by amyloidogenic Apoa-Il gene shortens the life span of mice but does not accelerate the rate of senescence. J Gerontol A Biol Sci Med Sci 1996:51:B295-B302.

56. Takeda T, Matsushita $T$, Kurozumi M, et al. Pathobiology of the senescence-accelerated mouse (SAM). Exp Gerontol 1997;32:117-127.

57. Kitagawa K, Naiki H, Takeda T, et al. Age-associated decreases in the messenger ribonucleic acid level and the rate of synthesis of apolipoprotein A-II in murine senile amyloidosis. Lab Invest 1994; 70:565-571.

58. Ozcan L, Tabas I. Role of endoplasmic reticulum stress in metabolic disease and other disorders. Annu Rev Med 2012;63:317-328.

59. Inagi R, Ishimoto $\mathrm{Y}$, Nangaku M. Proteostasis in endoplasmic reticulum-new mechanisms in kidney disease. Nat Rev Nephrol 2014; 10:369-378.

60. Groenendyk J, Sreenivasaiah PK, Kim do H, et al. Biology of endoplasmic reticulum stress in the heart. Circ Res 2010;107: 1185-1197.

61. Mishra S, Guan J, Plovie E, et al. Human amyloidogenic light chain proteins result in cardiac dysfunction, cell death, and early mortality in zebrafish. Am J Physiol Heart Circ Physiol 2013;305:95-103.

62. Ferreira N, Saraiva MJ, Almeida MR. Epigallocatechin-3-gallate as a potential therapeutic drug for TTR-related amyloidosis: "in vivo" evidence from FAP mice models. PLoS One 2012;7:e29933. 